\title{
Mercados de drogas, guerra e paz no Recife ${ }^{1}$
}

\author{
Jean Daudelin e José Luiz Ratton
}

Entre o início dos anos de 1980 e a metade da primeira década dos anos 2000, Recife esteve entre as capitais mais violentas do Brasil (Peres e Santos, 2005). Apesar de uma expressiva redução em suas taxas de homicídio nos anos que se seguem a 2007 (Pereira et al., 2016), há um claro recrudescimento das taxas de mortalidade violenta intencional a partir de 2014. A discussão sobre causalidade dos homicídios é complexa e envolve múltiplos fatores explicativos, mas parte significativa dessa violência pode ser atribuída, direta ou indiretamente, aos próprios mercados de drogas (Misse, 2007; Ratton et al., 2011; Zaluar, 2004). A despeito disso, a literatura sociológica sobre o funcionamento desses mercados e os mecanismos específicos de produção da violência ainda é bastante reduzida.

Este artigo tem por objetivo discutir as eventuais relações entre as dinâmicas internas de distintos mercados de drogas na cidade do Recife e a natureza mais ou menos violenta desses mercados. Atenção especial foi dada ao mercado de crack e aos mercados de drogas de classe média (drogas sintéticas, cocaína em pó, MDMA, maconha) ${ }^{2}$.

A análise aqui proposta tem por base um conjunto de 53 entrevistas confidenciais com usuários e vendedores de drogas, bem como acadêmicos, assistentes sociais,

1. A pesquisa realizada para este artigo foi apoiada pelo Insight Program do Social Sciences and Humanities Research Council do Canada (435-2014-1275). O protocolo para a coleta de dados foi aprovado pelo Comitê de Ética da Pesquisa da Carleton University (projeto 103339).

2. De forma semelhante a Grillo (2008), o conceito de classe média com o qual operamos é pensado como uma categoria nativa, abrangendo os estratos sociais que se reconhecem como tal. 
profissionais de saúde, terapeutas, médicos, policiais, juízes e promotores. As entrevistas foram realizadas entre setembro de 2015 e maio de 2016 e buscaram coletar informações sobre todos os mercados de drogas locais. Adicionalmente, os autores realizaram observação direta em diversos locais públicos onde ocorre venda de drogas e pesquisa nas versões on-line dos jornais diários que circulam na cidade do Recife ${ }^{3}$.

Mercados de drogas, ilegalidade e violência

Parte significativa da pesquisa acadêmica especializada estabelece algum tipo de ligação entre drogas ilícitas e violência. Paul Goldstein (1985) sugere que as possíveis relações entre as duas podem ser subsumidas em três mecanismos básicos: o primeiro, a violência farmacológica, seria derivado do efeito das drogas em si, gerando um comportamento violento da parte dos usuários, o que poderia também "convidar" à violência contra eles; o segundo está relacionado com os atos violentos praticados por usuários de droga para garantir o financiamento do consumo de drogas; por fim, há a violência sistêmica, que é resultado dos "padrões agressivos tradicionais de interação dentro do sistema de uso e distribuição de drogas", ou seja, do funcionamento do próprio mercado de drogas. Este último tipo de violência está ligado fundamentalmente, mas não exclusivamente, à ilegalidade do mercado de drogas.

Pesquisas posteriores dão suporte às intuições de Goldstein. Altas doses de cocaína (Nutt, 2012, pp. 185-187) e metanfetamina (McKetin et al., 2014) estão associadas com comportamento violento. Etnografias do consumo e do tráfico de crack (Bourgois, 2003; Goffman, 2014; Williams, 1990; Anderson, 1999; Venkatesh, 2009) mostram como pequenos crimes cometidos por usuários compulsivos de crack podem ser endêmicos, com indivíduos roubando de familiares e amigos para garantirem o consumo, produzindo tensões, violência e morte. Contudo, muitos trabalhos sugerem que as dinâmicas de mercado desempenham um papel central na conexão entre drogas e violência. Melo (2015) demonstra a dominância dos fatores sistêmicos sobre a violência farmacológica e aquela produzida pela compulsão econômica ${ }^{4}$. Goldstein et al. (1997, p. 118) mostram que 85\% dos homicídios

3. O presente artigo faz parte de pesquisa mais ampla coordenada pelos autores, intitulada Violência e governança da ilegalidade: dos mercados de drogas às prisões. A investigação em curso busca compreender as dinâmicas dos mercados de drogas na América Latina, seus condicionantes e suas implicações. Atenção especial é dada às relações entre mercados de drogas e violência. A primeira etapa (2015-2016), realizada em Pernambuco, já foi concluída; a segunda (2017-2019) está programada para ser realizada nos outros estados do Nordeste.

4. Mesmo tendo negligenciado o papel dominante de controle do mercado do crack e as eventuais relações dessa dominância com o declínio dos homicídios em São Paulo (Feltran, 2008, 2012; Biondi e Marques, 2010; Willis, 2016). 
estudados por ele em Nova York estavam ligados às dinâmicas do mercado de crack, enquanto fatores farmacológicos respondiam por 3\%, a compulsão econômica, por $7 \%$, e fatores diversos e combinados, por $6 \%$ do total. Os resultados da pesquisa de Sapori et al. (2010) na área metropolitana de Belo Horizonte também demonstram a predominância da violência sistêmica.

Atualmente, há praticamente um consenso que liga a maior parte da violência dos mercados de drogas à ausência tanto de direitos de propriedade formais, como de garantia da execução de contratos ou de mecanismos de resolução de disputas. Todas essas situações estariam ligadas à ilegalidade das drogas e aos limites que tal situação impõe ao funcionamento tranquilo desses mercados. De fato, a proibição é largamente vista, tanto na academia como nos círculos de políticas públicas, como a principal razão pela qual as drogas ilegais estão associadas a tanta violência (Werb et al., 2011; LSE Expert Group, 2014; Miron, 2004).

Todavia, vários trabalhos têm desafiado o consenso dominante e questionado a universalidade dessas reivindicações. Em outras palavras, argumenta-se que a proibição, apesar de estar vinculada à violência em vários mercados de drogas, não é condição para sua ocorrência. Peter Reuter, por exemplo, afirma que "mesmo sem a proteção dos estados e dos tribunais, mercados de drogas ilícitas são geralmente pacíficos" (2009, p. 275), para em seguida especificar as principais circunstâncias sob as quais eles se tornam violentos, prestando atenção nas dinâmicas intra e interorganizacionais. Skarbek e Leeson também mostraram que os mercados ilegais podem ser bastante funcionais e que "a anarquia funciona melhor que pensamos", mesmo para mercados de drogas na era do encarceramento em massa (Leeson e Skarbek, 2010; Skarbek, 2014). Alguns estudos de casos apresentam conclusões similares (Coomber, 2015; Hammersvik, 2015).

O questionamento da associação quase imediata entre mercados de drogas e violência é consistente com um conjunto significativo de evidências. Mesmo nos Estados Unidos, a maior parte da violência parece estar - ou, mais precisamente, tem estado - concentrada em torno dos mercados de crack em áreas pobres (Rainerman e Levine, 1997). A disseminação de drogas mais recente daquele país - metanfetaminas (Reding, 2009), opioides prescritos para o controle da dor e heroína do tipo black tar (Quinones, 2015) - não tem sido acompanhada por um aumento na taxa de homicídios, embora a mortalidade por overdose tenha crescido muito (CDC, 2013).

Os mercados de drogas de natureza pacífica mais conhecidos são os que fornecem drogas para consumidores de classes médias e altas dos países desenvolvidos. O consumo amplo e muitas vezes pesado de cocaína em pó, metanfetamina, ecstasy, maconha e, nos anos recentes, de designer drugs simplesmente não tem associação com altos níveis de violência. $\mathrm{Na}$ etnografia de "traficantes de residências universi- 
tárias", Mohamed e Frisvold (2011) documentaram o funcionamento aberto, amplo e absolutamente pacífico dos mercados de drogas nos campi das universidades da costa oeste dos Estados Unidos.

Não está claro, contudo, em que medida esse quadro também se repete nos mercados de drogas de classe média dos países em desenvolvimento. Poucos estudos têm discutido as relações entre consumo de drogas das elites e das classes médias e violência nesses países (Grillo, 2008; Daudelin e Ratton, 2016a).

Em suma, há uma inconsistência no quadro geral proposto por várias análises que consideram a ilegalidade, em si, como o determinante quase exclusivo da violência que, muitas vezes, prevalece nos mercados de drogas. O fato de a maior parte da violência ligada a drogas ocorrer nos mercados ilegais não diz muito sobre o que produz essa violência: é preciso identificar mecanismos mais específicos que deem sentido às condições e às circunstâncias em que os mercados ilegais se tornam violentos.

A existência da proibição legal e do amplo conjunto de políticas que a Guerra às Drogas propõe não implica automaticamente que a violência será generalizada ou mesmo comum. A violência sistêmica, como compreendida por Goldstein (1985), que deriva das disfunções dos mercados, precisa ser desdobrada em explicações factíveis, tornando visíveis os mecanismos particulares que fazem alguns mercados, em determinadas circunstâncias, mais propícios à disfuncionalidade do que outros.

Tentaremos identificar estes mecanismos complementares nas seções que se seguem.

\section{Mercados abertos e fechados}

Entre as potenciais explicações para a natureza pacífica ou violenta dos mercados de drogas em Recife, enfatizamos aquela que examina sua natureza - abertos ou fechados, cobertos ou descobertos - e sua associação com maiores ou menores graus de funcionalidade (ou de disfuncionalidade) ${ }^{5}$.

Enquanto estranhos podem interagir em mercados abertos, apenas pessoas que se conhecem e confiam umas nas outras podem fazê-lo em mercados fechados (Eck, 1998; Sampson, 2001; Harocopos et al., 2005; Mohamed e Fritsvold, 2011). Esses últimos são mais seguros e menos violentos por várias razões. Em primeiro lugar, as transações podem facilmente ser mantidas em segredo, tornando as perturbações provocadas pela atuação policial mais difíceis e com resultados improváveis. O roubo realizado por outsiders é também implausível, o crédito, quando existe, é obtido

5. Os autores traduziram closed and open markets como mercados abertos e fechados, e covert and overt markets como mercados cobertos e descobertos. 
facilmente - o que pode ser explicado pelo alto nível de confiança nas relaçóes pessoais - e, provavelmente, será pago. Em tais mercados, a violência física, ou a ameaça do seu uso, é efetivamente substituída pela sanção social (desaprovação, implícita ou não, vergonha, ostracismo e, em última instância, exclusão).

Um mercado aberto ilegal envolve atores que não se conhecem. Sem uma autoridade para regular transações, a desconfiança prevalece, e a possibilidade de fraude, tanto para compradores como para vendedores, é alta. Intercâmbios entre estranhos ocorrem em uma atmosfera tensa, e a possibilidade de que um ou outro sejam policiais ou informantes aumenta ainda mais a tensão das interações (Eck, 1998; Sampson 2001; Mohamed e Fritsvold, 2011; Sapori et al., 2006).

O grau de abertura do mercado de crack do Recife depende da posição em que ele está localizado na cadeia de distribuição. Os estratos mais altos do atacado são amplamente fechados e envolvem pessoas que se conhecem, tendo estabelecido relações de negócio de longa duração, desenvolvendo laços de confiança e mesmo de respeito entre si. No entanto, se formos para a parte mais baixa da cadeia de distribuição, no varejo, a necessidade de recrutar e de lidar com o maior número possível de usuários faz com que o mercado precise ser aberto.

Ao mesmo tempo, contudo, há um grau de regularidade nas transações, em larga medida devido à natureza compulsiva do uso de crack e à frequência do consumo produzida pela dependência. Visto que determinado ponto de venda ou um traficante particular foi escolhido, usuários costumam utilizar a mesma boca, construindo laços de confiança e favorecendo a ocorrência daquilo que, na literatura econômica e da ciência política, é denominado jogos muitas vezes repetidos (Engle-Warnick e Slonim, 2006). Dito de outro modo, embora o mercado do crack seja de fácil acesso para usuários potenciais, ele é aberto apenas de uma forma limitada.

Em contrapartida, todos os mercados de classe média que examinamos em Recife são fechados, porém em diferentes níveis. Os "grandes" traficantes buscam o produto fora do estado ou do país, mas, uma vez que a droga esteja na cidade, ela será vendida apenas para um pequeno grupo de intermediários conhecidos. Estes últimos conhecem bem os consumidores que somente compram para grupos de amigos, que em geral não são próximos desses intermediários. Por fim, se deixarmos de lado a cada vez mais rara compra direta de pequenas quantidades de maconha ou de crack em bocas, a distribuição final é realizada em grupos fechados de amigos. Mesmo as compras realizadas em bares são mediadas por conhecidos próximos, com o comprador potencial sendo referenciado para o vendedor por um amigo, o qual estabelece o contato ou pode mesmo comprar para ele. Em todos os casos, as relaçóes são estáveis no tempo, algumas vezes antecedendo o envolvimento no mercado ou mesmo o consumo do produto. 
Vendas de drogas sintéticas e de cocaína em grandes festas, e de inalantes durante o carnaval, constituem a única exceção a esta regra dos mercados fechados (a maconha é vendida livremente e prontamente compartilhada entre estranhos nesses contextos) (Daudelin e Ratton, 2016b).

\section{Mercados cobertos e descobertos}

Muitos autores não diferenciam mercados cobertos de fechados, e descobertos de abertos (Sampson, 2001; Harocopos et al., 2005; Kennedy e Wong, 2009; Mohamed e Fritsvold, 2011). Propomos, contudo, trabalhar com tais distinções, porque as situações às quais os mercados dizem respeito não se sobrepõem e os caminhos pelos quais eles produzem (ou não) violência são diferentes.

Um mercado descoberto envolve trocas físicas que são públicas, visíveis e, como resultado disso, baseadas em um espaço determinado (mesmo que esse espaço mude de lugar dentro de uma área, como é o caso de muitas bocas). Isso cria um ambiente que é inerentemente inseguro, porque potenciais competidores serão tentados a conquistar os espaços físicos onde as transações ocorrem e, ainda, porque os assaltantes sabem que há compradores com dinheiro e vendedores com produtos que convergem para os mesmos espaços. O problema é ampliado para os mercados ilícitos, pois eles são vulneráveis tanto a assaltantes e ladrões, como à polícia.

Transações cobertas, por contraste, têm lugar em espaços privados e bem protegidos ou mesmo em ambientes virtuais. De fato, os mercados mais cobertos têm como base a internet e são aqueles que vendem drogas com a mais alta potência por volume (LSD e sintéticos em particular), fazendo também o transporte do material de modo altamente discreto. Tanto para os espaços privados, como para os espaços virtuais, pouco ou nenhum custo adicional está envolvido com a proteção das transações, pois é muito difícil para potenciais assaltantes saberem quando e onde as transações ocorrerão e quem participará delas.

Muitos mercados cobertos, entretanto, têm algum espaço territorial definido e, consequentemente, vulnerabilidades ao roubo e às apreensões policiais: quantidades significativas de drogas necessitam ser buscadas a centenas ou milhares de quilômetros de distância, armazenadas de forma segura em algum lugar e distribuídas fisicamente. Para as drogas de classe média, o mercado não tem base territorial fixa, ao mesmo tempo que, no varejo, a quantidade de droga transportada e vendida é pequena. Torna-se mais fácil escondê-las e as transações podem ocorrer em espaços privados. Por outro lado, o atacado dessas mesmas drogas permanece vulnerável à intervenção policial e a algum tipo de ataque. Como desdobramento disso, podemos concluir 
que a vulnerabilidade relativa dos níveis mais altos de distribuição dos mercados de drogas de classes médias pode acarretar alguma forma de violência.

Os mercados de drogas descobertos mais conhecidos são as street-corners e as casas de crack dos guetos urbanos das grandes cidades norte-americanas, assim como as bocas e as cracolândias das metrópoles brasileiras. Em todos esses casos, os vendedores raramente escondem suas transações e com frequência consomem droga nos pontos de venda. Esses locais são bastante perigosos para os participantes do mercado, inclusive os espectadores, e estão, obviamente, associados com altos níveis de violência.

Mercados cobertos não devem ser confundidos com mercados fechados. Muitos mercados fechados são cobertos, e a maioria dos mercados abertos são descobertos. Todavia, a dark-web-based Silk Road ${ }^{6}$ era coberta e aberta, como são os outros mercados de drogas baseados na internet (Bartllet, 2015).É mais difícil pensar em um exemplo de mercado fechado e descoberto, mas a venda aberta de drogas caras (como a cocaína em pó), realizada entre amigos em festas, pode ser um tipo provável. Do ponto de vista da vulnerabilidade e da possibilidade de violência, mercados fechados e cobertos são mais seguros, enquanto mercados abertos e descobertos são mais perigosos, sendo os casos híbridos - abertos e cobertos, ou fechados e descobertos - situações intermediárias do ponto de vista da violência.

A proporção significativa de usuários que são dependentes, assim como seus padrões intensivos de consumo, aumenta a visibilidade dos mercados de varejo do crack, se os compararmos a quaisquer outros mercados de drogas. Em Recife, os estratos mais altos do mercado de distribuição do crack não apresentam esse problema, pois suas transações ocorrem de forma secreta, em lugares escondidos e rotativos (informações obtidas nas entrevistas). No varejo, contudo, o mercado é completamente descoberto: as vendas ocorrem em locais bem conhecidos pelos usuários ou potenciais usuários, por vizinhos e pela polícia. Muitas vezes, o consumo é feito no próprio local da venda ou perto dele. $\mathrm{O}$ varejo do crack é uma atividade aberta e todos os informantes concordam que as bocas e suas vizinhanças são locais propícios a furto, roubo, assassinato e confronto entre gangues ${ }^{7}$. Some-se a isso o fato de que as intervenções policiais podem levar a confrontos, provocando a morte tanto de traficantes como de moradores dessas áreas populosas onde funcionam as bocas (informações obtidas nas entrevistas).

6. Durante muitos anos, o principal mercado de drogas baseado na internet.

7. A eliminação ou o enfraquecimento de um rival - que tem um produto melhor ou um ponto de venda mais bem localizado - parece ser o motivo principal para as guerras territoriais entre grupos que têm fortes ligações com seus territórios. Note-se, contudo, que a tensão existente entre as gangues é, no mais das vezes, anterior à chegada dos mercados de drogas, o que revela o enraizamento social da violência. 
Por outro ângulo, não é difícil notar que os traficantes e consumidores de classe média, em Recife, geralmente negociam em mercados cobertos e fechados. Nossos informantes indicaram que as drogas sintéticas também são procuradas na internet com bastante frequência, até mesmo por "grandes" traficantes, e simplesmente enviadas pelo correio. $\mathrm{O}$ fato de as transaçôes não virtuais serem geralmente realizadas através das mídias sociais, com algum tipo de codificação ou comunicação eletrônica, torna esses mercados ainda mais escondidos (cobertos). Disponibilidade, marcação de encontros, como também detalhes das transações (quantidades e preços) são organizados confidencialmente. A crescente sofisticação dos mecanismos de investigação do sistema de justiça criminal representa um risco que esses mercados devem reduzir, exatamente por serem dependentes da tecnologia. Esse perigo, porém, parece estar limitado espacialmente pela pequena escala das transações. Os negócios e os acordos desses mercados aparentemente desaparecem com facilidade em meio ao conjunto de comunicações produzido pelo intenso tráfego de informações das mídias das camadas médias.

A paz que reina nos mercados de classe média, de acordo com as evidências levantadas, está associada em grande medida ao fato de eles serem fechados e cobertos, ao contrário do que predomina nos mercados de crack, abertos e descobertos, o que os torna vulneráveis a diferentes tipos de ataque e perturbação interna ou externa. Mas há outras características que tornam os primeiros ainda mais protegidos e os últimos bem mais vulneráveis à violência. Embora a capacidade explicativa das variáveis discutidas acima pareça robusta o suficiente para construir um relato hipotético da situação, propomos a inclusão de alguns fatores adicionais, que podem contribuir para a compreensão do funcionamento desses mercados.

\section{Consignação e crédito como fontes da violência}

O débito é uma fonte de violência importante nos mercados de drogas. Impossibilitados de usar os meios legais, traficantes têm poucas alternativas a não ser ameaçar ou usar a força para obrigarem os compradores a reembolsar vendas ou a quantidade exata de drogas oferecidas em consignação. A violência é um recurso largamente utilizado em um contexto em que, simplesmente, retirar os inadimplentes da lista de clientes ou permitir que eles busquem novos fornecedores (competidores) parece contraprodutivo.

Mercados que usam pagamento em dinheiro e à vista são mais fáceis de manejar. As vendas são iniciadas e terminadas, com pouco monitoramento ou custos de transação. Mercados de crédito, pelo contrário, envolvem cadeias de transações complexas que consomem tempo e recursos para seu manejo. Também necessitam 
ser sustentáveis ao longo do tempo, pois é preciso avaliar as chances que o débito tem de ser pago, manter relatórios sobre dívidas, coletar informações sobre devedores. Por outro lado, os credores precisam estabelecer e efetivar mecanismos para o ressarcimento dos débitos. $\mathrm{O}$ débito tem sido largamente associado à violência que prevalece nos mercados ilegais, sendo o caso mais conhecido o das oficinas de cobro colombianas (Castillo V., 2015).

Recife não parece ser uma exceção a esse quadro, e o débito não pago é a causa de violência mais comumente mencionada por nossos informantes. Há muitas razões para o lugar do débito no mercado de crack. A mais importante é que a população de usuários dessa droga ilícita é pobre e o consumo é caro. Uma única pedra é barata, mas muitas pedras são usadas em uma sessão e tal fato pode se repetir várias vezes ao dia ou mesmo se estender por dias, o que explica o alto custo do consumo de crack.

Isso coloca um desafio para o traficante, dada a alta competitividade do mercado. Uma sessão de uso de crack é cara, e uma remuneração mensal equivalente ao salário mínimo pagaria mais ou menos seis sessões de uso. Poucos usuários têm trabalho formal e a maioria dos que são dependentes não tem possibilidades ou habilidades para poupar o dinheiro a ser utilizado para uma sessão de consumo da droga. Sem a existência do crédito no mercado de crack, muitas vendas simplesmente não ocorreriam, ou os usuários teriam que ir para outro lugar, no qual houvesse a opção de pagar depois. Por fim, o fato de que uma única dose é barata, mas que é extremamente difícil não se entregar ao consumo excessivo, cria uma armadilha da qual muitos usuários não conseguem escapar (Daudelin e Ratton, 2016b).

O crédito e a consignação, muitas vezes, combinam-se em uma mistura que se revela fatal. Pequenos traficantes que dão crédito para clientes regulares, ou para amigos, podem ter que utilizar sua própria parte do negócio para pagar dívidas ou solicitar crédito a seus fornecedores. Observe-se que o não pagamento de dívidas, na ponta, pode reverberar em toda a cadeia de distribuição, com ameaças e efetivação de punição, ocorrendo de cima para baixo, na direção dos maus pagadores.

\section{"Superpoliciamento" no mercado do crack}

Mercados de drogas são altamente vulneráveis a ataques, inclusive dos agentes responsáveis pela aplicação da lei. Com um já considerável grupo de "grandes" traficantes competindo por ganhos significativos, a governança do atacado do mercado de crack local deveria ter sido (hipoteticamente) severamente afetada pelas prisões esporádicas de vários deles. Todavia, não fomos capazes de documentar quaisquer guerras de cartel em nossas entrevistas, pesquisa em jornais locais e em mais de duas décadas de observação da cena recifense na área de segurança pública. 
A mesma história não ocorre ao observarmos a parte mais baixa da cadeia de distribuição. O varejo do crack é constantemente afetado pela ação policial. Entre 2010 e 2015, foram registradas mais de 17 mil apreensões de crack, quase 3 mil por ano. $O$ peso médio da apreensão é de 42 gramas, o que sugere que varejistas relativamente pequenos são os principais alvos da polícia (Gomes de Castro Neto, 2016). As entrevistas deixam claro que os usuários e os pequenos traficantes regularmente têm suas drogas apreendidas pela polícia, ou são obrigados a pagar por elas, seja com dinheiro ou com serviços sexuais.

A pressão policial parece causar estragos no frágil sistema de débitos, forçando constantemente usuários, "aviõezinhos", "vapores” e traficantes do varejo a renegociarem acordos, aos quais estão presos por conta da situação de pobreza em que se encontram, pelo uso compulsivo que fazem do crack ou pela dependência dessa substância. Além disso, a frágil economia local, da qual muitos usuários dependem para financiar o uso do crack, também é interrompida, reduzindo as opções de receita desses atores a furtos e roubos. A combinação de todos esses fatores parece desempenhar um papel central nos níveis gerais de violência que caracterizam o mercado de crack local.

Por outro lado, o tratamento dos mercados de classe média pelo sistema de justiça criminal deve ser considerado um fator importante para explicar seu funcionamento "suave" e não violento. De forma geral, a atitude das polícias e do Judiciário diante desses mercados, especialmente no nível do varejo, pode ser considerada de uma negligência benigna (mas que reflete os padrões seletivos da atividade policial). Embora a imprensa relate esporadicamente a apreensão de LSD, ecstasy ou maconha entre usuários e traficantes de classe média, as entrevistas com policiais, vendedores e compradores mostram claramente que aqueles não são a prioridade ou mesmo uma preocupação significativa das autoridades do sistema de justiça. As razões são muitas: falta de recursos, alto custo para entrar em redes fechadas e cobertas, baixa chance de condenação, posição social e influência dos envolvidos. Por último, do ponto de vista das autoridades, está o fato de que os mercados de classe média não são violentos se comparados aos do crack nas comunidades pobres, o que explicaria sua baixa posição na agenda de prioridade supostamente estruturada pelas implicações violentas dessas atividades ilegais. Obviamente, a atuação desigual de policiais e operadores do sistema de justiça nos diferentes mercados tem consequências distintas para grupos sociais diversos (Azevedo, 2005).

Isso cria um interessante paradoxo já sugerido em várias pesquisas: a perturbação exercida pela polícia desempenha um papel importante na manutenção e no aumento da violência que campeia nesses mercados. A ação policial em tais casos exacerba a violência, disparando guerras de sucessão e competição territorial entre organizações 
criminosas envolvidas com o tráfico de drogas. Tal ação, portanto, destruiria a cadeia de distribuição e criaria tensões sobre confiscos dentro da cadeia de valor.

Em Recife, isso só acontece nos mercados do crack. Aqueles de drogas sintéticas, entre outras outras substâncias, para a classe média, constituem-se como espaços da Pax Narcótica, expressão usada para designar o regime informal que dominava antes que o então presidente do México, Felipe Calderón, desencadeasse uma guerra contra o narcotráfico (Chabat, 2010).

Violência e "subpoliciamento" em áreas pobres

Estudos norte-americanos recentes sobre redução de homicídios mostram que "a dissuasão focada" (Kleiman, 2009; Kennedy, 2009) pode ter um impacto substancial sobre os níveis de homicídio, reduzindo-os mesmo na ausência de qualquer esforço especial para conter o tráfico de drogas, com o qual a violência pode ser associada.

Em Recife, a introdução de um programa de segurança pública destinado principalmente à redução de homicídios, o Pacto pela Vida, foi seguida por uma queda notável nas taxas de homicídio (Ratton et al., 2014; Silveira et al., 2013). Por outro lado, o exame detalhado de Jill Leovy (2015) sobre as investigações de homicídios em Los Angeles, mostra que as maiores taxas de homicídio ocorrem em bairros pobres com população de maioria negra, em função dos baixos investimentos e esforços realizados na contenção e na dissuasão da violência nessas localidades. Esse argumento remete à famosa discussão sobre a violência inerente ao "Código da Rua" - assim como às formulações de Victor Rios sobre o subpoliciamento em Oakland (2010) -, que está parcialmente ligada à falta de policiamento eficaz nas regióes da cidade onde vive boa parte da população negra (Anderson, 1999). Da mesma forma que um superpoliciamento pode perturbar os mercados de drogas com efeitos letais, uma dissuasão eficaz pode reduzir rapidamente as taxas de homicídio.

Com exceção do período em que o Pacto pela Vida concentrou seus esforços na investigação e na dissuasão dos crimes contra a vida ${ }^{8}$, o policiamento discriminatório, ou pelo menos seletivo, tem sido a norma no Brasil, e Recife não é exceção (Lima et al., 2014).

Violências praticadas por pobres contra pobres raramente são investigadas, e as operações policiais contra gangues são, com frequência, indistinguíveis de execuções sumárias, com unidades de policiamento especializadas apresentando graus elevados

8. No decorrer da implementação do Pacto pela Vida, iniciada em 2007, o foco original na redução de homicídios perdeu força, especiamente a partir de 2011, deixando espaço para a política convencional de apreensão de drogas. 
de letalidade (Cano, 1998; Bueno, 2014). Some-se a isso a combinação de dois fatores que dificultam ainda mais o trabalho policial: a grande desconfiança dos pobres em relação à polícia e a forte ligação das gangues que controlam o mercado de drogas no varejo com os bairros e as comunidades onde atuam (Arias, 2006), que, por um lado, suscita confiança e, por outro, provoca medo. As taxas de esclarecimento de crimes são desanimadoras (informações obtidas nas entrevistas) e o efeito dissuasório geral da atividade policial sobre os homicídios é muito baixo (Ratton e Cireno, 2007). Dois últimos fatores alimentam a desconfiança dos pobres em relação à polícia e contribuem diretamente para a reprodução da violência: a impunidade diante da letalidade da ação policial em áreas de baixa renda e as extorsões praticadas por agentes públicos nesses espaços (Bueno Nunes, 2014).

Em suma, onde quer que o super-enforcement da proibição de drogas amplifique as disfuncionalidades e as tensões que prevalecem nos mercados de drogas, seja em Recife ou em Los Angeles, a ausência de uma dissuasão efetiva de comportamentos violentos promove o apelo a suas formas mais extremas, incluindo homicídios, uma opção que, no contexto descrito, apresenta custos relativamente baixos. Muitas das disfunções do mercado de crack - especialmente a prevalência do uso da violência física - resultam do sub-enforcement da segurança, pensada aqui como bem público, em espaços que já são socialmente vulneráveis. Nossa análise em Recife aproxima -se da proposta de Victor Rios (2011) sobre o impacto disfuncional e combinado do super e do subpoliciamento em Oakland, Califórnia.

\section{Padrões de consumo e seu impacto sobre a violência}

Os padrões de consumo do crack aumentam a probabilidade de ocorrência da violência, especialmente quando combinados com as características já descritas desse mercado. Os entrevistados sugerem que a combinação de compulsão, dependência e consumo em grupo contribuem para a tensão e a violência que caracterizam o mercado do crack em Recife.

As sessões em que o crack é consumido são momentos tensos: os usuários ficam fissurados e paranoicos, aumentando a chance de haver episódios violentos. Anderson (1999) descreve em seu trabalho essa imersão no consumo, que deixa o usuário totalmente alienado, sem conexão com que está à sua volta.

Ademais, a necessidade de sustentar o efeito da droga leva a seu uso intensivo e excessivo, tendo por consequência a realização de ações muitas vezes violentas para a obtenção de mais pedras. Afora isso, a falta de cuidado na escolha dos locais de consumo aumenta a vulnerabilidade dos usuários e a visibilidade das bocas ou áreas de venda (que, nesse sentido, são descobertas), o que traz maior risco de furto ou assalto para 
usuários, de operações policiais ou mesmo de ataques de gangues de outros territórios.

Conforme foi discutido, as drogas no mercado de classe média são pagas à vista, porque os clientes possuem renda bem mais alta e as drogas consumidas são relativamente baratas. Além disso, a classe média consome drogas com propósitos recreativos e, de forma diferente daquela que é observada no uso de crack, o consumo problemático parece ser algo excepcional, diminuindo ainda mais a necessidade de crédito, com a aquisição do produto podendo facilmente ser adiada quando não há dinheiro.

O uso menos problemático de drogas nos mercados de classe média também contribui para manter esses mercados cobertos e fechados, com baixa frequência de transação e pequenas redes de comercialização. Isso, consequentemente, facilita o manejo do acesso ao mercado nas situações em que ainda não existe confiança entre vendedor e comprador. Há pouca dúvida de que a predileção dos consumidores das classes médias por drogas sintéticas e por maconha - drogas que não estão associadas com altos níveis de dependência (Nutt, 2012) - contribui significativamente para a tranquilidade que reina nesses mercados. $\mathrm{O}$ fato de essas drogas não estarem associadas a um comportamento violento - como acontece com o álcool, a metanfetamina e o crack - amortece ainda mais os riscos de violência. Em outras palavras, e voltando para a tríade de Goldstein (1985), efeitos farmacológicos mais amenos e pequena compulsão econômica combinam-se, reforçando as características sistêmicas que tornam esses mercados relativamente pacíficos, ao passo que a violência dos efeitos do crack agudiza as disfuncionalidades sistêmicas desse mercado.

\section{Considerações finais}

A análise aqui empreendida sugere que a brutalidade do mercado do crack em Recife está ligada, primeiramente, a uma combinação explosiva de consumo compulsivo e dependente, situação de pobreza, consumo aberto, uso extensivo de crédito, consignação no nível do varejo e policiamento disruptivo, com baixa dissuasão da violência.

Em contrapartida, os mercados de classe média na cidade são ativos, bem organizados e, apesar disso, essencialmente pacíficos. A quase ausência de violência pode ser explicada pelo fato de esses mercados serem fechados e cobertos, o que os mantém relativamente protegidos da violência. No entanto, outros fatores reforçam essas características: o tamanho relativamente pequeno da renda disponível nesse mercado (diante das possibilidades das camadas médias); o fato de que o crédito é quase ausente; o uso não problemático da maior parte dos consumidores (o que está relacionado com o tipo de droga e seus efeitos sobre a existência ou não de compulsão econômica); e a ausência de esforço sério das autoridades do sistema de justiça criminal de perturbá-lo. 
Um ponto importante a ser mencionado diz respeito à dificuldade de se compreender os mercados de drogas separando-os de seus contextos sociais. Tomemos alguns exemplos: a importância do crédito e da consignação, como fontes da violência nos mercados de crack, e sua ausência nos mercados de drogas de classe média; ou mesmo a atratividade exercida pela alta renda que pode ser obtida com a venda de crack por jovens em situação de pobreza e com poucas alternativas para a obtenção de rendimentos similares, enquanto o envolvimento de jovens de classe média em atividades sistemáticas de venda de drogas parece muito menos atrativo economicamente (a renda disponível é menor e menos atraente, se comparada às possibilidades de renda legais, o que favorece a menor participação de jovens nesses mercados) (Daudelin e Ratton, 2016a e b). Em outras palavras, estamos falando do enraizamento social dos mercados ilegais de droga, que parece ser um componente inescapável de qualquer tentativa de compreender a violência (ou sua ausência) dentro desses mercados, e portanto merece um tratamento analítico especial.

À guisa de conclusão, levantamos quatro questões como inspiração para futuras pesquisas. Em que medida setores socialmente privilegiados são capazes de construir e isolar suas atividades ilegais de contextos sociais extremamente violentos? $\mathrm{O}$ relativo sucesso dessas estratégias seria uma outra expressão das profundas desigualdades que assolam esses países (Daudelin e Ratton, 2016c)? Em que medida a paz que vigora nos mercados de drogas de classe média e a violência que predomina nos mercados de crack das áreas pobres das grandes cidades brasileiras estão ligadas diretamente a políticas públicas distintas e discriminatórias, especialmente no campo da segurança pública? (Idem). E, por fim, podem as discussóes sobre políticas públicas aprender algo sobre o gerenciamento pacífico de mercados ilegais, que poderia ser estendido (ou aplicado) àqueles mercados onde a violência é mais prevalente? 


\section{Referências Bibliográficas}

Anderson, Elijah. (1999), Code of the street. Nova York, Norton.

Arias, Henrique Desmond. (2006), Drugs and democracy in Rio. Chapel Hill/Londres, University of North Carolina Press.

Azevedo, Rodrigo Ghringhelli. (2005), "Criminalidade e justiça penal na América Latina”. Sociologias, 7 (13): 212-241.

BARTLETT, Jamie. (2015), The dark net. Londres, Windmill Books.

BAstos,Francisco.(2012),“Structuralviolence in the context of drug policy and initiatives aiming to reduce drug-related harm in contemporary Brazil: a review”. Substance Use \& Misuse, 47 (13-14): 1603-1610.

Biondi, Karina \& Marques, Adalton. (2010), “Memória e historicidade em dois 'comandos' prisionais". Lua Nova, 79: 39-70.

Bourgois, Philippe. (2003), In search of respect: selling crack in El Barrio. 2. ed. Nova York, Cambridge, Cambridge University Press.

Bueno, Samira. (2014), Bandido bom é bandido morto: a opção ideológico-institucional da política de segurança pública na manutenção de padrôes de atuação violentos da polícia militar paulista. São Paulo, dissertação de mestrado, Fundação Getulio Vargas, FGV.

Castillo V., Maria del Pilar. (2015), “La relación entre oficinas de cobro y pandillas: un caso de agencia”. The Latin American and Iberian Journal of Law and Economics, Berkeley, 1 (2): 42-68.

Castro Neto, Antonio Gomes de. (2016), Avaliação da distribuição geográfica e da composição quimica de inalantes e crack apreendidos no estado de Pernambuco. Recife, tese de doutorado, Ciências Farmacêuticas, Universidade Federal de Pernambuco.

CANo, Ignacio. (1998), Letalidade policial no Rio de Janeiro: a atuação da justiça militar. Rio de Janeiro, Iser.

CDC Center for Disease Control (2013), "Opioids drive continued increase in drug overdose deaths”. Press Release (Atlanta GA: Center for Disease Control, February 20). Disponível em http://www.cdc.gov/media/releases/2013/p0220_drug_overdose_deaths.html, consultado em 6/6/2014.

Снават, Jorge. (2010), "Combatting drugs in Mexico under Calderon: the inevitable war". Cide Documento de Trabajo, 205. Disponível em http://www.cide.edu/publicaciones/ status/dts/DTEI\%20205.pdf, consultado em 3/2/2011.

Coomber, Ross. (2015), "A tale of two cities: understanding differences in levels of heroin/ crack market-related violence”. Criminal Justice Review, 40 (1): 7-31.

Daudelin, Jean \& RatTon, José Luiz. (2016a), "Islands of peace: middle class drug markets in Recife, Brazil". Paper prepared for the conference of the Latin American Studies Association. Nova York, 27-30 maio 2016. 
. (2016b), "Crack violence in Recife: micromechanics of a dysfunctional market" (unpublished manuscript).

. (2016c), "Inequality and drug violence: the crack market in Recife, Brazil". Paper prepared for the conference of Adlaf Congress - Gewalt und Ungleichheit (Violencia y Desigualdad). Berlim, 20-21 jun. 2016.

ECK, John. (1998), "A general model of the geography of illicit retail marketplaces". Crime and Place, 4: 67-93 (número organizado por J. Eck e D. Weisburd).

ENGLE-WARNICK, Jim \& SLONIM, Robert L. (2006a), "Learning to trust in indefinitely repeated games”. Games and Economic Behavior, 54 (1): 95-114.

Feltran, Gabriel. (2010), “Crime e castigo na cidade: os repertórios da justiça e a questão do homicídio nas periferias de São Paulo”. Cadernos CRH, 23 (58): 59-73.

Friman, H. Richard. (2009), "Drug markets and the selective use of violence". Crime, Law and Social Change, 52 (3): 285-295.

Goffman, Alice. (2014), On the run: fugitive life in an American city. Chicago, University of Chicago Press.

Goldstein, Paul. (1985), “The drugs/violence nexus: A tripartite conceptual framework”. Journal of Drug Issues, 15 (4): 143-174.

Grillo, Carolina C. (2008), Fazendo o doze na pista: um estudo de caso do mercado ilegal de drogas entre os jovens de classe média do Rio de Janeiro. Rio de Janeiro, dissertação de mestrado, Sociologia e Antropologia, Universidade Federal do Rio de Janeiro.

HAMMERSviK, Eirik. (2015), "Four barriers and a set of values that prevent violence among cannabis growers”. International Journal of Drug Policy, 26 (3): 290-295.

Harocopos, Alex \& Hough, Mike. (2005), Drug dealing in open-air markets: problem-oriented guides for police problem-specific guides series, n. 31. Washington DC., Department of Justice Office of Community Oriented Policing Services. Disponível em http://www. cops.usdoj.gov/html/cd_rom/solution_gang_crime/pubs/DrugDealinginOpenAirMarkets. pdf, consultado em 12/8/2012.

Kennedy, David M. (2010), Deterrence and crime prevention: reconsidering the prospect of sanction. Londres/Nova York, Routledge.

\& Wong, Sue-Lin. (2009), The high point drug market intervention strategy. Washington DC., Department of Justice, Office of Community Oriented Policing Services, July. Disponível em https://www.highpointnc.gov/police/docs/The_High_Point_Drug_Market_Intervention_Strategy.pdf, consultado em 4/1/2016.

Leeson, Peter \& Skarbek, David. (2010), “Criminal constitutions”. Global Crime, 11 (3): 279-298.

Leovy, Jill. (2015), Ghettoside: A true story of murder in America. Nova York, Spiegel \& Grau. Lima, Renato et al. (2014), Crime, polícia e justiça no Brasil. São Paulo, Contexto.

LSE Expert Group on the Economics of Drug Policy (2014), Ending the drug wars. Londres, 
LSE/Ideas. Disponível em http://www.lse.ac.uk/IDEAS/publications/reports/EndingDrugWars.aspx, consultado em 5/8/2015.

Mello, João M. P. de. (2015), "Does drug illegality beget violence? Evidence from the crack-cocaine wave in São Paulo”. Economía, 16 (1): 157-185.

McKetin, Rebecca et al. (2014), "Does methamphetamine use increase violent behaviour? Evidence from a prospective longitudinal study". Addiction 109 (5): 798-806.

Miron, Jefrey A. (2004), Drug war crimes: the consequences of prohibition. Oakland, Independent Institute.

Misse, Michel. (2007), "Mercados ilegais, redes de proteção e organização local do crime no Rio de Janeiro". Estudos Avançados, 21 (61): 139-157.

Mohamed, A. Rafik \& Fritsvold, Erik D. (2011), Dorm room dealers: drugs and the privileges of race and class. Reprint edition. Boulder/Londres, Lynne Rienner.

NutT, David. (2012), Drugs without the hot air, without the hot air. Cambridge, UIT Cambridge Ltd.

Owens, Emily Greene. (2011), "Are underground markets really more violent? Evidence from early 20th century America”. American Law and Economics Review, 13 (1): 1-44.

(2014), "The American temperance movement and market-based violence". American Law and Economics Review, 16 (2): 433-472.

Pearson, Geoffrey \& Hoвbs, Dick. (2003), "King Pin? A case study of a middle market drug broker". The Howard Journal of Criminal Justice, 42 (4): 335-347.

Pereira, Débora V. S. et al. (2016), "The homicide drop in Recife, Brazil: a study of crime concentrations and spatial patterns". Homicide Studies, February, 1-18.

Peres, Maria Fernanda T. \& Santos, Patricia C. (2005), "Mortalidade por homicídios no Brasil na década de 90: o papel das armas de fogo". Revista de Saúde Pública, 39 (1): 58-66.

Quinones, Sam, (2015), Dreamland: the true tale of America's opiate epidemic. Londres, Bloomsbury.

Ratton, José Luiz \& Cireno, Flávio (2007), "Violência endêmica - homicídios na cidade do Recife: dinâmica e fluxo no Sistema de Justiça Criminal". Revista do Ministério Público do Estado de Pernambuco, Recife, vi: 17-157.

et al. (2011), "Configurações de homicídios em Recife: um estudo de caso". Segurança, Justiça e Cidadania: O Panorama dos Homicídios no Brasil, 3 (6), Brasília.

Ratton, José Luiz et al. (2014). "Pact for life and the reduction of homicides in the state of Pernambuco". Stability: International Journal of Security and Development. 3 (1).

Reinarman, Craig \& Levine, Harry. (1997), "The crack attack: politics and media in the crack scare". In: ReInARMAN, Craig; Levine, Harry (eds.). Crack in America: demon drugs and social justice. Londres, University of California Press, 1997.

Reding, Nick (2009), Methland: the death and life of an American small town. Nova York, Bloomsbury. 
Reuter, Peter. (2009), "Systemic violence in drug markets". Crime Law and Social Change, $52(3): 275-284$.

\& CAUlkins, Jonathan P. (2003), “Does precursor regulation make a difference?”. Addiction, 98 (9): 1177-1179.

Rios, Victor M. (2011), Punished: policing the lives of black and Latino boys. Nova York, New York University Press.

Rui, Taniele Cristina. (2014), Nas tramas do crack: etnografia da abjeção. São Paulo, Terceiro Nome, Unicamp.

SAmpson, Rana. (2001), Drug dealing in privately owned apartment complexes. Washington, DC, Department of Justice, Office of Community Oriented Policing Services.

SAPORI, Luis Flavio et al. (2012), "Mercado do crack e violência urbana na cidade de Belo Horizonte”. Dilemas: Revista de Estudos de Conflito e Controle Social, 5 (1): 37-66.

Silveira, Raul et al. (2013), "Avaliação de política pública para redução da criminalidade violenta: o caso do programa Pacto pela Vida do Estado de Pernambuco" (manuscrito).

Skarbek, David. (2014), The social order of the underworld. Oxford/Nova York, Oxford University Press.

Venkatesh, Sudhir Alladi. (2009), American project: the rise and fall of a modern ghetto. Cambridge, Harvard University Press.

Werb Dan et al. (2011), "Effect of drug law enforcement on drug market violence: a systematic review”. International Journal of Drug Policy, 22: 87-94.

Williams, Terry. (1993), Crackhouse: notes from the end of the line. Reading, MA, Addison-Wesley.

Willis, Graham Denyer. (2015), The killing consensus: police, organized crime, and the regulation of life and death in urban Brazil. Oakland, University of California Press.

Zaluar, Alba. (2004), Integração perversa: pobreza e tráfico de drogas. Rio de Janeiro, Editora da FGV. 


\section{Resumo}

Mercados de drogas, guerra e paz no Recife

Este artigo procura discutir as possíveis conexões entre o funcionamento de diferentes mercados de drogas e a violência na cidade do Recife. Os autores propõem que mercados abertos e descobertos, como o do crack, são mais propícios à violência, ao contrário dos mercados fechados e cobertos (mercados de drogas das classes médias). Outros fatores contribuem para a presença de mais ou menos violência em cada mercado de drogas pesquisado: a existência ou não de crédito e consignação, o consumo mais ou menos problemático de cada droga e o tipo de atuação policial em cada mercado de drogas. A observação direta do funcionamento de alguns desses mercados, a pesquisa em jornais diários locais e entrevistas com usuários e vendedores de drogas, profissionais da área de saúde, assistentes sociais, psicólogos, juízes, promotores e policiais foram as estratégias metodológicas utilizadas.

Palavras-chave: Mercados de drogas; Violência; Crack; Drogas e classes médias; Polícia.

\section{Abstract}

Drug markets, war and peace in Recife

This article discusses the possible connections between the functioning of various drug markets and violence in Recife. The authors propose that open and uncovered markets, such as the crack, are more prone to violence, unlike the closed and covered markets (the drug markets of the middle classes). Other factors contribute to the presence of more or less violence in each drug market analysed: the existence or nonexistence of credit and consignment, the more or less problematic use of each drug and the type of police action in each drug market. In addition to direct observation of the behavior of some of these drug markets and research in local newspapers, interviews were conducted with users and drug sellers, health professionals, social workers, therapists, judges, prosecutors and police officers.

Keywords: Drug markets; Violence; Crack; Drugs and middle classes; Police.

Texto recebido em 19/1/2017 e aprovado em 9/2/2017. DoI: 10.11606/0103-2070.ts.2017.1 25670 .

JEAN DAUDELIN é professor associado da Norman Paterson School of International Affairs, Carleton University, Ottawa. E-mail: jean.daudelin@gmail.com.

JOSÉ LUIZ RATTON é professor associado do Departamento de Sociologia da Universidade Federal de Pernambuco. E-mail: jl.ratton@gmail.com. 
